\title{
Re-Placing the Desert in the Conservation Landscape: Charisma and Absence in the Gobi Desert
}

\author{
Stephen Lezak
}

School of Geography and the Environment, University of Oxford, South Parks Road, Oxford OX1 3QY, UK; stephen.lezak@gmail.com

Received: 1 December 2018; Accepted: 28 December 2018; Published: 29 December 2018

\begin{abstract}
Across the Gobi Desert in China and Mongolia, millions of newly planted trees struggle to survive amid adverse ecological conditions. They were planted by a wide variety of actors in an attempt to protect, restore, or modify the local environment, despite evidence of their negative consequences upon local ecosystems. This paper investigates how these afforestation projects both challenge and affirm recent theoretical work on conservation, while also providing key insights into the decision-making framework of land management across the world's third largest desert region. This analysis, supported by evidence from corporate practice, government policy, and participant observation, builds primarily on the work of Jamie Lorimer and other authors who identify the charisma of certain species as a primary driver of contemporary conservation. But the case of afforestation in the Gobi is inadequately explained by a desire to protect individual species; rather, I show how the charisma at the level of the landscape influences conservation practice. I extend this analysis to suggest that the management of deserts worldwide may be mediated by their perception as absent or empty spaces, thus explaining projects like afforestation which seem to re-place rather than conserve. Using the framework of absence and presence to better understand land use and environmental governance could have implications extending well beyond the Gobi Desert.
\end{abstract}

Keywords: absence; afforestation; charisma; China; conservation; desertification; Gobi; Mongolia

\section{Introduction}

In recent decades, the practice of environmental conservation has become the subject of sustained ethnographic inquiry. Researchers writing in the traditions of anthropology, environmental history, and science and technology studies have examined how land management and its constituent sciences are shaped not only by objective biophysical referents, but also by cultural inputs and human bias. This paper builds on this literature by examining these recent theoretical developments in the arid and semi-arid landscape of the Gobi Desert in Mongolia and China, a markedly different setting to the bucolic countryside of Europe and the dense forests of North America from which these theories originated. In particular, I examine the widespread practice of drylands afforestation, which is supported by individual, corporate, and public actors across the Gobi region. This analysis suggests that environmental conservation in the world's third-largest desert is inexplicable by recent critical scholarship that focuses rather narrowly on the role of charisma in individual species as the drivers of conservation management practice [1-3]. In the Gobi, where afforestation efforts are largely unconcerned with inter-species distinctions, what underlies conservation decision-making instead is an epistemology of ecological wellbeing situated at the scale of the landscape itself. Put differently, conservation actors are engaged in projects to promote landscape-wide flourishing, with little regard for the welfare of constituent species. In this context, the role of charismatic organisms-usually upheld as central to the "conservation assemblage" [1]—is secondary at best. Perhaps critiques thus far have paid so much attention to the proverbial trees that they've failed to see the forest. 


\section{Background}

Contemporary critiques of conservation practice arose in part from the wider cultural turn in anthropology and philosophy in the late 20th Century. As early as the 1990s, the perceived marginalization of non-Western perspectives in land management led to sustained calls for integrating more diverse voices into the politics and policies of environmental governance [1]. "Fortress conservation" [2] - the exclusion of human inhabitants from protected natural areas-became the flashpoint of a latent conversation within the conservation movement: what does it mean to protect and care for the unbuilt environment? Were competing visions of conservation owed to information deficits and inappropriate biases, or could there exist multiple conflicting but equally legitimate answers to the questions at hand?

Traditionally, the answers to these questions were provided by conservation biologists, who represent themselves as simultaneously positivist and normative in their practice [3]. The conservationist is at once the impartial scientist and also the pro-environmental activist [4,5]—like Dr. Seuss' Lorax, who "speak[s] for the trees" [6]. But critics have challenged the orthodoxy that conservation biology practitioners can simultaneously lay claim to ethical truth and natural fact. Without ever doubting good intentions, questions arose as to whether the positivist enterprise of conservation could really achieve the detached impartiality to which it lay claim [4].

William Cronon's essay, "The Trouble with Wilderness" [7], has become a cornerstone of this perspective. Writing in the mid-1990s, Cronon argues that the "natural"-as distinct from the "human" - is a cultural invention, made possible by industrialization and urbanization, when people first began to build environments that looked and felt radically different from farmland or forests. It was in precisely this vein that authors began to raise pressing questions about whether conservation biology itself is a culturally and politically mediated practice. These critiques suggest that a concept such as biodiversity or wilderness may not be "a true object that science progressively uncovers, but ... an historically produced discourse" [4] (p. 54). Jamie Lorimer [3], in particular, has written at length about how conservation science and policy emerge from an assemblage of human and nonhuman interactions [8]; the scientific knowledge and management decisions that result are contingent, dynamic, political, and disquietingly subjective.

The way in which society, political interests, and aesthetic bias come to bear upon these discourses is not simply a matter of intellectual inquiry; the role of conservationists as experts of environmental management brings real-world consequence to their practice [9]. What's more, the backdrop of global environmental change raises the stakes significantly. How landscapes transform in the Anthropocene depends directly on how humans deliberate what constitutes good conservation and what is healthy or harmful to nonhuman life. Yet even as many environmentalists embrace a cross-disciplinary perspective (and as "The Trouble with Wilderness" enters the canon of environmental studies reading lists), some conservationists bristle at the question of whether their own scientific methods are ensnared in cultural entanglements. It seems that many of these researchers and practitioners perceive the science of ecology as relatively insulated from the silty waters of culture. They assert that at a time of global environmental destruction, critical theorists who question the epistemological underpinnings of conservation can inadvertently arm anti-environmentalism or otherwise sew disunity among an already fragmented movement $[10,11]$. This sustained divide between traditional ecology and a conservation practice that acknowledges contingency $[3,12]$ continues to frustrate efforts to assimilate theory into practice. This paper focuses on the theory-practice nexus of one ecosystem in particular: the arid and semi-arid drylands of the Gobi Desert.

In the following pages, I focus on the practice of afforestation (planting trees where they did not previously grow) in the Gobi Desert in Northern China and Southern Mongolia (see Figure 1). I present three miniaturized "scenes", each an independent case study of an afforestation site, ordered by increasing scale. I begin with a firsthand anthropological account from fieldwork conducted in the Noyon administrative district in the summer of 2017; the second scene is a study of corporate environmental remediation; the third examines national afforestation policies in Mongolia and 
China. While this regional analysis affirms much of the scholarship that identifies human bias in conservation practice, it also poses a challenge to a key theoretical tenet: that conservation management is explicable by a species-level ontology of the charisma of particular organisms in combination with their broader ecological role $[3,13]$. Jamie Lorimer defines nonhuman charisma "as the distinguishing properties of a nonhuman entity or process that determine its perception by humans and its subsequent evaluation" [13] (p. 915). At the level of the species—"the basic unit of conservation biology" [14] (p. 52) - environmental protection exhibits a tension between protecting a group of designated organisms and using alternative epistemologies to determine desirable ecological outcomes. The former tends to prevail, generating a species-centered practice that Ernest Small calls "the New Noah's Ark" [15] for its necessary exclusion of a large share of organisms. Those species that are easier to identify and observe, aesthetically remarkable, and thrilling to encounter receive a disproportionate share of attention from the global assemblage of conservation actors [15-17]. One analysis found that the "flagship species" of environmental groups are best explained in terms of marketing theory rather than ecological significance [18].

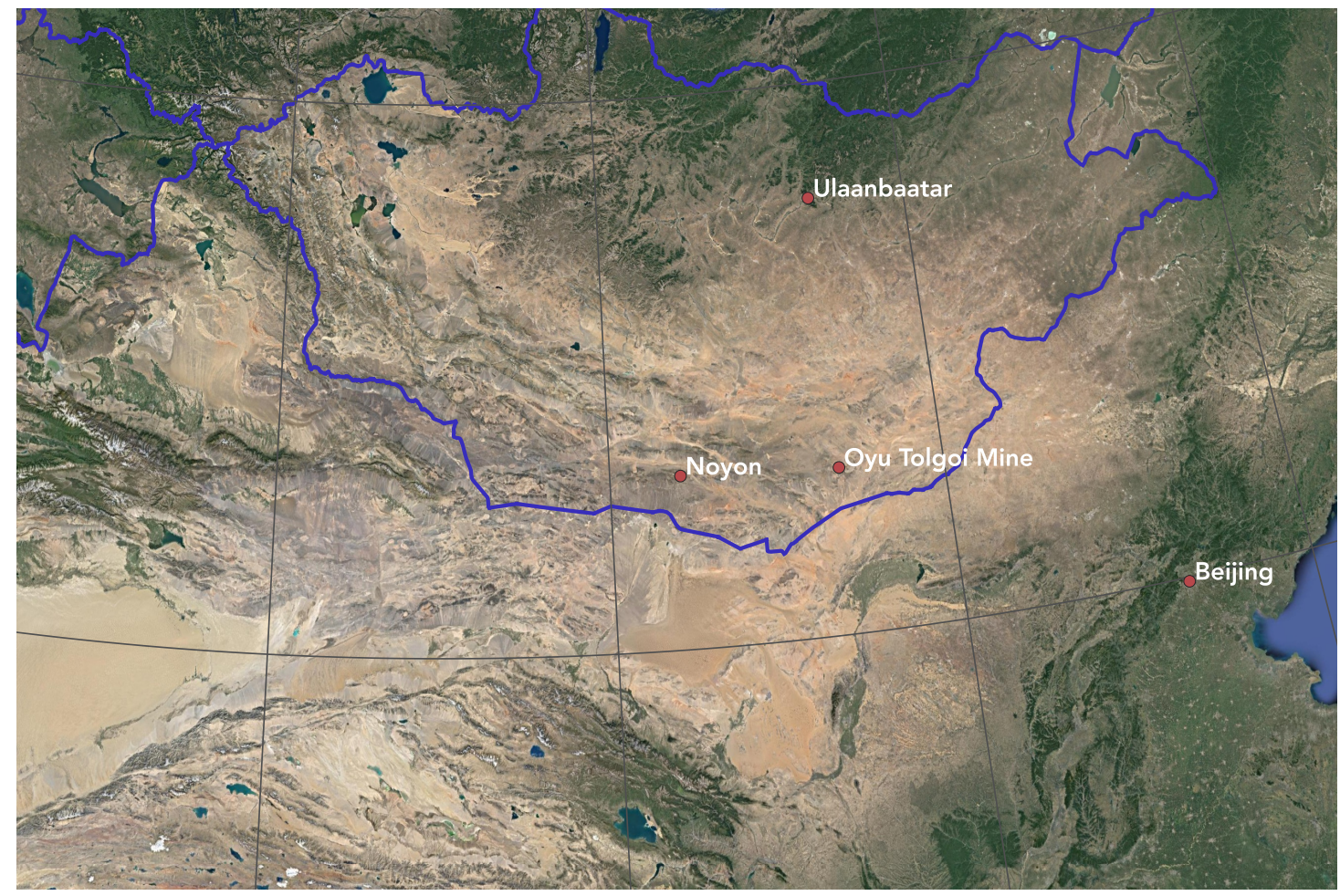

Figure 1. The Gobi Desert, with Noyon and Oyu Tolgoi. Imagery: Landsat/Copernicus; Data SIO; NOAA; US Navy; NGA; GEBCO (2018). Data: Google (2018).

The case of Gobi afforestation, however, refuses to conform to this model of conservation. In this regional instance, the planting of trees as an environmental intervention is insoluble in a species-level ontology of environmental conservation. As shown below, afforestation is undertaken with a desire to protect the environment and justified in scientific (rather than aesthetic) vernacular, yet the region-wide effort is neither ecologically rational nor explained by a desire to protect one or more particular species. The following scenes suggest that the mobilization of private industry and government resources to plant trees in the Gobi is responding instead to nonhuman charisma at the level of the landscape. Specifically, the aesthetic perception of deserts as barren, lifeless spaces leads actors to associate afforestation with environmental protection. Lacking in "natural" charisma, the protection of the desert is realized as its re-placement. In this instance, conservationists are filling the metaphorical ark with whatever charismatic biomass is closest at hand-many of the scraggly native scrub species are evidently of minimal interest. The discussion section of this paper addresses this in further detail by 
considering whether the landscape-level charisma of the Gobi is an exceptional case, or whether it might generalize across more regions and biomes, particularly those landscapes perceived of as absent before human eyes.

\section{The Champion Herder}

Despite the relative lack of plant agriculture [19], trees have always had a precious place in Gobi society, and deliberate tree-planting in the region dates at least to the 13th Century [20]. But preindustrial silviculture was made extremely difficult by the region's climate. The Gobi is the world's third largest desert, with a current size over 2 million $\mathrm{km}^{2}$ [21]. Its edges are semi-arid, with annual rainfall of less than $200 \mathrm{~mm}$, but in its driest regions, precipitation is well below $100 \mathrm{~mm}$ annually [22]. On the Mongolian (north) side of the desert, cultivated agriculture is a rare sight, prohibited by climate and the relative lack of groundwater wells. The landscape accommodates scrub vegetation, including large areas of grassland on which nomadic and semi-nomadic herders graze a variety of large herbivores [23]. Scattered trees are occasionally found in canyons and ephemeral streambeds, well-positioned to capture a torrent of summer rainfall [22,23]. Marco Polo, who traveled across Asia and met with the Emperor, Kublai Khan, noted that tree planting was a common policy in the Mongolian Empire. Perhaps anticipating nine-hundred years of environmental theory, the Venetian observed that both nature and culture were written into the Empire's afforestation policy: a hybrid of rural land planning and spiritual appeasement.

There is another regulation adopted by the Great Khan, equally ornamental and useful. At both sides of the public roads he causes trees to be planted, of a kind that become large and tall ... to point out the road - when the ground is covered with snow.

... It may be added that the Great Khan is the more disposed to plant trees because astrologers tell him that those who plant trees are rewarded with long life. [20] (pp. 228-229)

This sort of hybrid land planning—partly practical, partly spiritual—remains common today. I found it epitomized by one "champion herder" who lives just beyond the dozen mirrored canyons of the Noyon Syncline (see Figure 1). He had achieved public recognition for having over 1000 animals in his herd. His economic success enabled him to plant an unruly grove of trees amid a landscape otherwise dominated by coarse gravel. In the summer of 2017, the elderly grandfather toured me around his miniature forest. I followed him into a small depression below the hill on which he made his seasonal camp (like many Mongolian herders, he moved with his animals several times each year). At the bottom of the basin we passed the pump house which drew up ancient rainfall into a maze of irrigation hoses. A lush grove of young trees lay just beyond, the tallest reaching about four meters in height. The old man explained that he had planted exactly 108 trees: an "auspicious number" for Mongolians, he noted.

When I asked why he planted the grove, he told me he had a desire to "protect nature". He was aware that his small forest was a local biodiversity hotspot for birds and insects. He also gave away seeds to his neighbors and expressed his pride that South Gobi Province was leading the tree planting movement in Mongolia. When we sat down in a tiny gazebo in the center of the grove our conversation turned to more spiritual matters. Three benches were arranged in the shade around a table made from a tree trunk too wide to have come from his relatively young plantation. The herder spoke with sadness about the local mining activity and the decline of nomadic herding. He said that the rise of one and the tapering off of the other had both contributed to local land degradation. I was reminded of similar conversations I've had with cattle and sheep ranchers in Western Wyoming, USA. Our conversation was cut short by the arrival of the local shaman-he had come to conduct ceremonies on the herder's behalf, that he might better understand what was troubling the local land spirits.

Not unlike Kublai Khan's, this champion herder's tree planting expressed an epistemology of ecological well-being that drew upon observed ecological phenomena but relied equally upon culture, spirituality, and aesthetics in order to assess and draw conclusions from objective (i.e., "out there") 
referents. What's more, the herder was not especially concerned with the pre-interventionist state of the landscape-he was improving rather than conserving. This may seem strange, given that the Gobi is not short on threatened charismatic species; for instance, the elusive snow leopard is the focus of extensive conservation efforts [24]. Yet afforestation at any scale does not appear to figure into a larger plan to protect these large mammals, or to protect any particular species for that matter. Rather, the champion herder wanted to "protect Nature", writ-large. He looked out onto the steppe and saw a lack of flourishing. The sparse desert scrub did not seem worth cultivating-it did not convey the sort of vibrancy that a healthy environment would feature. In response, the herder aimed to create a livelier landscape: most relevant was not the charisma of one species or another, but the cumulative absence of aesthetic charisma from the ecosystem he called home.

A similar sentiment can be found in the discourse of Mongolian Buddhist religious leaders. The proceedings from the 2005 Northern Buddhist Conference on Ecology and Development, hosted in Ulaanbaatar, features a summary of recent reforestation efforts in the Gobi. Whilst described as "conservation", the planting of elm trees is advocated as "an organic means of commemorating the lives lived" whilst making "an important contribution to fighting desertification" [25]. Land management, in this case, belongs to the realms of both culture and nature, science and spirituality-without pretense of pure rationality. While the herder's grove is hardly an example of modern conservation biology, it offers an archetype for how a landscape-level epistemology of an ecosystem motivates environmental action that is entirely unconcerned with the welfare of already-existing charismatic species. I open with this scene to hold a mirror to more modernist conservation practices in the Gobi, examining differences and similarities alike. The following two scenes explore these parallels.

\section{The Transnational Mining Company}

Roughly $200 \mathrm{~km}$ east of the champion herder's summer camp is Oyu Tolgoi, until recently the world's largest undeveloped combined copper and gold mine [26]. The mine is jointly owned by the Mongolian government and Rio Tinto, one of the world's largest mining companies [27]. Expected to someday account for one-third of Mongolia's GDP [28], Oyu Tolgoi has become a point of constant reference in national political conversations. The mine is renowned for voluntarily pursuing an ambitious target of "net-positive impact", aimed at more-than-offsetting any ecological harm caused in the course of its operations. To meet this goal, Oyu Tolgoi is employing "biodiversity offsets", detailed in an expansive environmental and social impact assessment (ESIA) [29]. The design and implementation of the Oyu Tolgoi remediation plan has been praised for setting a new standard in Mongolian extractive industry-a welcome contrast to the routinely poor practices that are commonplace in the sector. Twice-annual audits for ESIA compliance have been undertaken since 2013 by independent consultancies in Canada and Italy, with results published online alongside shareholder reports and an encyclopedic environmental management plan. Oyu Tolgoi was routinely praised in my conversations with Mongolian NGO employees, who felt it set a new standard for extractive industry in the country.

But even Oyu Tolgoi is planting trees in the Gobi where before there were none. In 2014, Oyu Tolgoi planted over 10,000 saxaul trees, using irrigated plots to ensure the trees' survival [30]. Curiously, Oyu Tolgoi's own ESIA states that the mine expects "no certain losses to offset" [29] on the local saxaul groves. That is, Oyu Tolgoi is planting trees not as a like-for-like remediation, but rather as an offset to other ecological harm, such as water contamination, airborne dust, and habitat destruction. The harm that Oyu Tolgoi has set out to remedy is not concerned with one species over another; like the champion herder, the perceived damage exists on a landscape-level ontology that is taxonomically irreducible. Within that framework, the planting of saplings is not about the trees per se; it is a socioecological compensation for other types of environmental harm. Such practices evoke what Mette High, in her research on Mongolian artisanal and small-scale (ninja) miners, calls cosmoeconomics. High documents the practice of corporate and small-scale miners employing lamas to conduct "appeasement 
ceremonies" at the groundbreaking of new mines, partly to placate angered land and water spirits [31] (p. 101).

There is an additional strangeness worth noting about Gobi afforestation. An abundance of evidence suggests that tree plantations in the Gobi Desert do more to exacerbate ecological degradation than repair it. Ecologists studying Gobi afforestation have written at length about the foolishness of planting trees in this arid and semi-arid region [32-34]. Rather than stabilizing topsoil and preventing desertification, newly-planted trees increase soil erosion by upsetting the surface water equilibrium due to increased evapotranspiration. Particularly in windy areas such as the Gobi, this increases evaporation and depletes soil moisture. The resulting topsoil is drier and more susceptible to wind- and waterborne sediment transport, further degrading soils and increasing desertification. Post-perturbation recovery in dry climates is a slow and difficult process, possibly requiring hundreds of years for an ecosystem to resemble its pre-disturbance state [35]. What passes as a biodiversity offset is more like a damage multiplier.

A report by the World Bank's East Asia and Pacific Environment and Social Development Department investigated several tree-planting initiatives in the Mongolian Gobi. In 2004, thirty-three million seedlings were planted in Mongolia across nearly ten-thousand hectares [22]. A partial survey of these planting sites yielded striking results: among those sites in the Gobi, none had a survival rate higher than eight percent; a majority of surveyed plots had no living trees at all. The reasons for this lack of success were numerous, but most often stemmed from inadequate management such as degraded fencing and insufficient irrigation. The World Bank report also highlighted poor site selection as a confounding factor: none of the Gobi sites were located in areas that could support trees without irrigation. The authors note that one site was located in an area where the water requirements of the saplings were $150 \%$ of annual rainfall. The report also noted a strong bias toward planting species that were particularly ill-suited to the Gobi climate. Even as native saxaul plantations struggled, much costlier Gobi sites were developed with elm, poplar, willow, and tamarix. These sites, roughly thirty times more cost-intensive per hectare than the saxaul sites, reveal a generous bias toward non-native or rarer tree species. Perhaps unsurprisingly, these trees that have received such a disproportionate share of resources bear little resemblance the scruffy demeanor of saxaul; they are archetypes of the forest: tall, lush aliens in the desert landscape.

In Oyu Tolgoi's 2017 shareholder report, a photo shows rows of smiling employees holding saplings beneath a vast nursery canopy [36]. Is it possible that this act of ecological charity is not so different from the champion herder's grove or from the trees that lined the avenues of 13th-Century Mongolia? Even this multinational mega-mine's practice of conservation maneuvers between biophysical referents and subjective preferences. At the end of the day, the irrigated saxaul grove near Oyu Tolgoi, exponentially larger than that of the champion herder, also represents a vision of ecosystem wellbeing that is neither wholly "cultural" nor entirely "natural", and is clearly invested in the flourishing of the landscape rather than the welfare of a subset of its charismatic inhabitants. The planting of trees at mining sites like Oyu Tolgoi shows landscape conservation taking the form of landscape substitution. Actors stage a recuperation by replacement, inserting organisms that did not and would not have existed otherwise. That this landscape-level conservation is practiced by a giant of global capitalism suggests that the champion herder mentioned above may be more of an exemplification than an exception.

\section{The National Policies}

Perhaps Marco Polo would not have been surprised to know that nearly a millennium after his visit, the Mongolian government once again mandates the planting of trees. The 2012 Minerals Law introduced a policy of exponential afforestation:

18.1 The central state administration in charge of geological and mining affairs shall exercise the following authority: 
...

18.2.11 to develop a method, a methodology and a procedure for planting ten trees for every cut down tree and foresting [sic]

...

114. The mandatory rehabilitation of environment affected by prospecting, exploration, mining and processing activities:

...

114.4 A license holder shall be obliged to plant 100 trees in place of each tree that was cut down in the course of prospecting, exploration, mining and processing activities. [37]

The central government has passed these laws despite the inability to sustain many tree plantations without groundwater irrigation, depleting fossil reserves that hydrogeologists classify as "non-renewable" [38].

This contemporary practice of state-sponsored afforestation also echoes 20th Century policies across Europe and Asia, in which high-modernist statecraft frequently turned to tree-planting. Nazi Germany, Mussolini's Italy, and the Soviet Union under Stalin all sponsored ambitious afforestation programs [39]. Of these, the earliest and longest-lived was the Soviet Union's "Great Stalin Plan for the Transformation of Nature", which sought to create nearly six million hectares of new forest to serve as shelterbelts along the southern border, intended to stop dry winds coming from Central Asia and increase precipitation in Southern Russia [39]. While these practices were concerned with environmental engineering and resource management, their proponents also saw landscape modification and conservation as a means to foster national identity and ecological nativism [40]. Dr. Konrad Guenther, a German conservationist, asserted in the early 1930s that "the chords of the German soul are tuned to nature. Let us allow nature to speak, and let us be happy to be German!" (qtd. in [39]). In all of these programs, the image of the forest seems to serve as nature's archetype: healthy, resilient, and worthy of protection.

The history of afforestation in the Gobi is relatively more recent. Qing-era China showed little interest in forest management, especially compared to the regenerative forestry practiced by Japan beginning in the 18th Century [41]. In the earth 20th Century, Chinese leaders including Mao Zedong showed little interest in environmental issues [39], but his successors have pursued an ambitious afforestation project for the past five decades. A US \$7 billion tree planting initiative has been underway since 1978 [42]. The Three-North Shelterbelt, also known as the Great Green Wall, is the world's largest tree planting project [43], an attempt to slow the northern winds coming across the Gobi and prevent soil erosion and airborne dust [44]. Fifty-billion trees [45] have been planted in the hopes of slowing the expansion of the desert and reducing the severity of regional dust storms that carry as far as Beijing [46]. It appears that this instance of afforestation- "the dominant ecological engineering program in China" [44] (p. 14)—has emerged without the same Tibetan Buddhist roots as its Mongolian counterparts, but persists despite ecologists' continued claim of its perverse outcomes. While China's National Forestry and Grassland Administration describes the Shelterbelt as a "great success" [47], Chinese ecologists have decried these afforestation efforts at length, for all the same reasons listed above [48]. As of 2005, the survival rate of trees planted as part of the Three-North Shelterbelt was 15\% [33]. Ironically, these efforts may be counteracting a decade-long upward trend in regional precipitation that led the Gobi to contract by as much as 18\% between 2000 and 2012 [21].

Is the Shelterbelt relevant to other instances of Gobi afforestation? The Great Green Wall is undoubtedly a conservation program, meant to "protect" non-arid landscapes from a desert which is perceived as encroaching. Nowhere in this discourse is there a consideration that desert itself might need protecting - it is as if the desert is separate from Nature in a way that the forest is not. Furthermore, the aims and methods of the Shelterbelt seem largely unconcerned with protecting vulnerable species. What seems to drive this ecological mega-project is the fear of an infectious absence 
in the Gobi. Chinese engineers have been tasked with its containment. The resulting conservation plan seems to embrace the ethic, don't just stand there—plant something! Evidently native species don't count.

Jiang Gaoming, an ecologist at the Chinese Academy of Sciences, astutely observes that the government is "trying to make forests, that is, planting trees in areas that did not have forests distributed, or are at least treeless in the last several thousand years" (quoted in [49]). The making of forests exhibits the characteristics of a completely secular, modernist, landscape-level ontology of conservation, but still vulnerable to the aesthetics of charisma. In this particular case, government land managers set out to do precisely what took place at Oyu Tolgoi and at the champion herder's home: to substitute one landscape with another, gardening in the name guardianship. It was as though the mere insertion of these saplings, with their own vital energy, would enliven a landscape threatened by infertility. In these acts of conservation, the Gobi is being re-placed with forest.

\section{Discussion: Geographies of Absence}

In these case studies, conservation practice is not fully reducible to ecological rationality and the allure of charismatic species. The planting of non-native trees across this desert expanse is irreducible in mainstream ecological and theoretical accounts of conservation. Rather, Gobi afforestation seems to involve a rowdy cast of characters that are rarely present in contemporary literatures of conservation planning and practice. In some instances (e.g., Section 3), environmental protection is primarily concerned with religiously-inflected aesthetics. In other instances, a modernist, interventionist vision of human-nature relations structures land conservation as engineering projects. But a common thread connects these: afforestation-as-conservation poses an important counternarrative to the conventional wisdom that conservation is primarily driven by species-level charisma.

To a large extent this paper builds upon the work of Lorimer [3] and others, showing how conservation is indeed a messy assemblage. But the context of the Gobi reveals an analytic container that is not fully sealed. To date, the dominant scholarship that frames conservation as a hybrid of natural science and cultural inputs has focused primarily on the charisma of plant and animal life [13], and on species in particular, as the drivers of a hybrid conservation assemblage that is more-than-human and more-than-science. Much of this is framed by discussions of "charismatic megafauna" - most often birds or large mammals—that disproportionately occupy the attention of conservation biologists' scientific practice.

In a telling illustration, a review of over 63.5 million UK biological records indicates that $65 \%$ of all entries document bird species. A further $22 \%$ concern vascular plants. The remaining $13 \%$ of total records spans all non-avian vertebrates, lower plants, fungi, and invertebrate life forms [50]. It is no surprise that these data focus on the most charismatic species of the British Isles and neglect those that less effectively captivate human interest. Jamie Lorimer, noting this genomic injustice, writes that "UK conservation is guided less by the panoptic logic of biodiversity and more by a taxonomy of nonhuman charisma" [3] (p. 75).

Yet in the context of Gobi afforestation, charismatic organisms do not seem to figure prominently in the logic of conservation. Indeed, biologists hired by mining companies and governments seem relatively uninterested in protecting indigenous life forms. Conservationists instead insert unthreatened species into an alien ecology, suggesting that a verdant, charismatic, synthetic landscape is preferable to a "natural" one. In this regional study, conservation management is not driven by the presence of charismatic species but rather by their absence-a quality that can only exist at the level of the landscape.

I close this paper with a conjecture: there is something about drylands that disrupts the role of species-level charisma in motivating land management. If true, this particular phenomenon could have important implications for how humans across cultures manage desertscapes. Conservation biology in landscapes with high net primary productivity usually takes the form of protecting what is (or was) already there, often framed around keystone or flagship species. By contrast, attempts to protect the Gobi take the form of inserting the largest possible organisms into a landscape frequently 
described as "barren" or "empty". ${ }^{1}$ Is this furnishing fullness to eliminate absence? Does an "empty" landscape connote sickness and a "full" one indicate health? I propose that absence itself may be a worthwhile object of study, to better understand the dynamics of landscape conservation in the deserts of the world.

Perhaps a more appropriate conservation strategy for the Gobi would not be invested in creating more life or filling a void. This would require disposing of our usual metaphors for understanding ecosystem health, e.g., as a body or a population [51]. Indeed, the naming of landscape-level charisma calls for a return to certain biophysical basics to counter this bias. Such an approach would embrace absence and shift focus to species diversity, resilience, equilibria, or geologic indicators such as soil transport and groundwater reserves. It would be critical of species-level ontologies with the architecture of flagships and keystones. It would be skeptical of top-down human interventions, particularly those that re-place the landscape with non-native critters. Above all, this approach would be cognizant of the discursive mode in which land managers represent—or misrepresent-the flourishing of landscapes.

A final question lingers: could this same geography of absence present itself in other ecosystems? There are parallels waiting to be drawn: consider the relatively high rate of alpine conservation compared with lowland conservation, or the precipitous state of global blue-water marine habitat-an altogether different type of desert but with an undeniable aura of absence [52]. Even further afield, we may consider how absence adds context to aerospace engineers' increasingly urgent warnings about the growing dangers of orbital space debris [53]. Taken as a whole, a much broader critique emerges, suggesting that the bulk of conservation practice is dedicated not just to charisma but to reinforcing presence — of mountains, large mammals, deep canyons, striking butterflies, mighty rivers, and forests. How might environmentalists better harness their resources and knowledge to protect those spaces that are, by nature, absent before our human eyes?

\section{Conclusions}

This paper traces the hybrid ecologies of the Gobi along the roots of its newly planted groves. How and why these afforestation programs emerged ties together ecology, charisma, modernity, and the geographies of absence. While the present analysis does not necessarily generalize beyond the Gobi, I see no compelling reason to suggest that it is limited to this one region. Jamie Lorimer has already illustrated the hybridity of conservation practice on a variety of scales.

In 2015, the conservation and ecology journal Oryx published a special issue on trees. Peter Crane writes in the opening editorial that "The charismatic megaflora are a gift to the whole of humanity bequeathed to us by millions of years of evolution" [54] (p. 378). It is difficult to imagine the same adulatory words written about seaweed, scrub, or the biotic communities in soils-those less charismatic flora and bacteria. It seems even less probable that the same could be written about "the desert" at large. This paper suggests that when charisma, presence, or cultural affinity cambers the perception of landscapes as healthy or ailing, land management can veer toward ecological irrationality-species need never enter the conversation. It appears that the afforestation efforts in the Gobi are exemplary of this. Identifying this phenomenon asks environmental managers to hold a mirror to their practice and interrogate biases-however large or small—that might influence how we shape and inhabit the deserts of the world.

Funding: The research was funded by the Economic and Social Research Council and the Global Challenges Research Fund, grant number ES/S000798/1; and by the University of Oxford John Fell Fund, grant number 00005620.

1 It bears noting that, more than most plants, trees have particularly anthropomorphic qualities (linguistically evidenced by their limbs, trunks, and crowns). In this sense, desert afforestation could be read as populating an absent landscape. 
Acknowledgments: I am deeply grateful to Ariell Ahearn and Troy Sternberg; this research would not have been possible without their generous mentorship. Olivia Ashmoore, Cavin Wilson, Michaela Korodimou, Daniel Lezak, and two anonymous reviewers provided comments on previous drafts. S. Soyolbold and M. Tserennadmid gave crucial support and guidance during fieldwork.

Conflicts of Interest: The author declares no conflict of interest.

\section{References}

1. Conservation and Mobile Indigenous Peoples: Displacement, Forced Settlement, and Sustainable Development; Chatty, D., Colchester, M., Eds.; Studies in Forced Migration; Berghahn Books: New York, NY, USA, 2002; ISBN 978-1-57181-841-6.

2. Brockington, D. Fortress Conservation: The Preservation of the Mkomazi Game Reserve, Tanzania; African Issues; International African Institute in Association with James Currey; Indiana University Press: Oxford, UK; Bloomington, IN, USA, 2002; ISBN 978-0-253-34079-5.

3. Lorimer, J. Wildlife in the Anthropocene: Conservation after Nature; University of Minnesota Press: Minneapolis, MN, USA, 2015; ISBN 978-1-4529-4428-9.

4. Escobar, A. Whose Knowledge, Whose nature? Biodiversity, Conservation, and the Political Ecology of Social Movements. J. Political Ecol. 1998, 5, 53-82. [CrossRef]

5. Robertson, D.P.; Hull, R.B. Beyond Biology: Toward a More Public Ecology for Conservation. Conserv. Biol. 2001, 15, 970-979. [CrossRef]

6. Geisel, T.S. The Lorax; Random House: New York, NY, USA, 1971; ISBN 978-0-394-82337-9.

7. Cronon, W. The Trouble with Wilderness: Or, Getting Back to the Wrong Nature. In Uncommon Ground: Rethinking the Human Place in Nature; Norton: New York, NY, USA, 1996; pp. 69-90.

8. Latour, B. Reassembling the Social: An Introduction to Actor-Network-Theory; Clarendon Lectures in Management Studies; Oxford University Press: Oxford, NY, USA, 2007; ISBN 978-0-19-925605-1.

9. Rutherford, S. Green governmentality: Insights and opportunities in the study of nature's rule. Prog. Hum. Geogr. 2007, 31, 291-307. [CrossRef]

10. Chaloupka, W. Jagged Terrain: Cronon, Soule', and the Struggle over Nature and Deconstruction in Environmental Theory. Strateg. J. Theory Cult. Politics 2000, 13, 23-38. [CrossRef]

11. Soulé, M.E. The Social Siege of Nature. In Reinventing Nature? Responses to Postmodern Deconstruction; Soulé, M.E., Lease, G., Eds.; Island Press: Washington, DC, USA, 1995; pp. 137-170, ISBN 978-1-55963-310-9.

12. Biro, A. Towards a Denaturalized Ecological Politics. Polity 2002, 35, 195-212. [CrossRef]

13. Lorimer, J. Nonhuman Charisma. Environ. Plan. D Soc. Space 2007, 25, 911-932. [CrossRef]

14. Braverman, I. Conservation without nature: The trouble with in situ versus ex situ conservation. Geoforum 2014, 51, 47-57. [CrossRef]

15. Small, E. The new Noah's Ark: Beautiful and useful species only. Part 2. The chosen species. Biodiversity 2012, 13, 37-53. [CrossRef]

16. Clucas, B.; McHugh, K.; Caro, T. Flagship species on covers of US conservation and nature magazines. Biodivers. Conserv. 2008, 17, 1517-1528. [CrossRef]

17. Minin, E.D.; Moilanen, A. Improving the surrogacy effectiveness of charismatic megafauna with well-surveyed taxonomic groups and habitat types. J. Appl. Ecol. 2014, 51, 281-288. [CrossRef]

18. Home, R.; Keller, C.; Nagel, P.; Bauer, N.; Hunziker, M. Selection criteria for flagship species by conservation organizations. Environ. Conserv. 2009, 36, 139-148. [CrossRef]

19. Sneath, D. Mongolia Remade: Post-Socialist National Culture, Political Economy, and Cosmopolitics; Amsterdam University Press: Amsterdam, The Netherlands, 2018; ISBN 978-90-485-4213-0.

20. Polo, M. The Travels of Marco Polo, the Venetian; Wright, T., Ed.; Bohn: London, UK, 1854.

21. Sternberg, T.; Rueff, H.; Middleton, N.; Sternberg, T.; Rueff, H.; Middleton, N. Contraction of the Gobi Desert, 2000-2012. Remote Sens. 2015, 7, 1346-1358. [CrossRef]

22. Mühlenberg, M.; Batkhishig, T.; Dashzeveg, T.; Drößler, L.; Neusel, B.; Tsogtbaatar, J. Lessons From Tree Planting Initatives in Mongolia; Mongolia Discussion Papers, East Asia and Pacific Environment and Social Development Department; World Bank: Washington, DC, USA, 2006.

23. Wesche, K.; Ronnenberg, K.; Retzer, V.; Miehe, G. Effects of large herbivore exclusion on southern Mongolian desert steppes. Acta Oecol. 2010, 36, 234-241. [CrossRef] 
24. Johansson, Ö.; McCarthy, T.; Samelius, G.; Andrén, H.; Tumursukh, L.; Mishra, C. Snow leopard predation in a livestock dominated landscape in Mongolia. Biol. Conserv. 2015, 184, 251-258. [CrossRef]

25. Robinson, J.; Verboom, G.; Urantsatsral, C.; Thrift, E. Northern Buddhist Conference on Ecology and Development, Summary of Sessions. Ulaanbaatar, Mongolia, 2005. Available online: http:/ /www.arcworld. org/downloads/UB_conference.pdf (accessed on 26 November 2018).

26. Anonymous. Halfway to Where? The Economist, 8 October 2011.

27. Kapelus, P. Mining, Corporate Social Responsibility and the "Community": The Case of Rio Tinto, Richards Bay Minerals and the Mbonambi. J. Bus. Ethics 2002, 39, 275-296. [CrossRef]

28. Anonymous. Mine, all Mine. The Economist, 21 January 2012.

29. The Biodiversity Consultancy. Fauna \& Flora International ESIA Appendix 5: Net Positive Impact forecast for the Oyu Tolgoi Project; The Biodiversity Consultancy: Cambridge, UK, 2012.

30. OT Plants Saxaul Trees to Restore Gobi Landscape. Available online: http:/ / en.mongolianminingjournal. com/content/57143.shtml (accessed on 26 November 2018).

31. High, M.M. Fear and Fortune: Spirit Worlds and Emerging Economies in the Mongolian Gold Rush; Cornell University Press: Ithaca, NY, USA, 2017; ISBN 978-1-5017-0754-4.

32. Cao, S. Why Large-Scale Afforestation Efforts in China Have Failed to Solve the Desertification Problem. Environ. Sci. Technol. 2008, 42, 1826-1831. [CrossRef] [PubMed]

33. Cao, S.; Tian, T.; Chen, L.; Dong, X.; Yu, X.; Wang, G. Damage Caused to the Environment by Reforestation Policies in Arid and Semi-Arid Areas of China. Ambio 2010, 39, 279-283. [CrossRef]

34. Cao, S.; Chen, L.; Shankman, D.; Wang, C.; Wang, X.; Zhang, H. Excessive reliance on afforestation in China's arid and semi-arid regions: Lessons in ecological restoration. Earth-Sci. Rev. 2011, 104, 240-245. [CrossRef]

35. Bailey, R.M. Spatial and temporal signatures of fragility and threshold proximity in modelled semi-arid vegetation. Proc. R. Soc. B Biol. Sci. 2011, 278, 1064-1071. [CrossRef]

36. Turquoise Hill Resources. Made by Mongolia: Annual Report 2017; Turquoise Hill Resources, Ltd.: Vancouver, BC, Canada, 2017.

37. Law of Mongolia: Minerals Law. Available online: http://en.mongolianminingjournal.com/content/38041. shtml (accessed on 26 November 2018).

38. Ma, J.; Ding, Z.; Edmunds, W.M.; Gates, J.B.; Huang, T. Limits to recharge of groundwater from Tibetan plateau to the Gobi desert, implications for water management in the mountain front. J. Hydrol. 2009, 364 , 128-141. [CrossRef]

39. Brain, S. The Great Stalin Plan for the Transformation of Nature. Environ. Hist. 2010, 15, 670-700. [CrossRef]

40. Williams, J.A. "The Chords of the German Soul are Tuned to Nature": The Movement to Preserve the Natural Heimat from the Kaiserreich to the Third Reich. Cent. Eur. Hist. 1996, 29, 339. [CrossRef]

41. Saito, O. Forest history and the Great Divergence: China, Japan, and the West compared. J. Glob. Hist. 2009, 4, 379. [CrossRef]

42. Li, M.; Liu, A.; Zou, C.; Xu, W.; Shimizu, H.; Wang, K. An overview of the "Three-North" Shelterbelt project in China. For. Stud. China 2012, 14, 70-79. [CrossRef]

43. Hanjie, W.; Hao, Z. A simulation study on the eco-environmental effects of 3N Shelterbelt in North China. Glob. Planet. Chang. 2003, 37, 231-246. [CrossRef]

44. Wang, X.M.; Zhang, C.X.; Hasi, E.; Dong, Z.B. Has the Three Norths Forest Shelterbelt Program solved the desertification and dust storm problems in arid and semiarid China? J. Arid Environ. 2010, 74, 13-22. [CrossRef]

45. Ahrends, A.; Hollingsworth, P.M.; Beckschäfer, P.; Chen, H.; Zomer, R.J.; Zhang, L.; Wang, M.; Xu, J. China's fight to halt tree cover loss. Proc. R. Soc. B Biol. Sci. 2017, 284, 20162559. [CrossRef] [PubMed]

46. Wang, X.; Dong, Z.; Zhang, J.; Liu, L. Modern dust storms in China: An overview. J. Arid Environ. 2004, 58, 559-574. [CrossRef]

47. Three-North Shelterbelt Program. Available online: http://english.forestry.gov.cn/ (accessed on 26 November 2018).

48. Jiang, G.; Han, X.; Wu, J. Restoration and Management of the Inner Mongolia Grassland Require a Sustainable Strategy. Ambio J. Hum. Environ. 2006, 35, 269-270. [CrossRef]

49. Jiang, H. China's Great Green Wall Proves Hollow. Epoch Times 2009, 29, 2009.

50. Burnett, J.; Copp, C.; Harding, P. Biological Recording in the United Kingdom: Present Practice and Future Development; UK Department of the Environment: Oxford, UK, 1994. 
51. Larson, B. Metaphors for Environmental Sustainability: Redefining Our Relationship with Nature; Yale University Press: New Haven, CT, USA, 2014; ISBN 978-0-300-20581-7.

52. Jackson, S.E. The water is not empty: Cross-cultural issues in conceptualising sea space. Aust. Geogr. 1995, 26, 87-96. [CrossRef]

53. Shan, M.; Guo, J.; Gill, E. Review and comparison of active space debris capturing and removal methods. Prog. Aerosp. Sci. 2016, 80, 18-32. [CrossRef]

54. Crane, P. Can we save the charismatic megaflora? Oryx 2015, 49, 377-378. [CrossRef]



(c) 2018 by the author. Licensee MDPI, Basel, Switzerland. This article is an open access article distributed under the terms and conditions of the Creative Commons Attribution (CC BY) license (http:/ / creativecommons.org/licenses/by/4.0/). 